\title{
DO SENSO COMUM À CIÊNCIA: A TEORIA DO CONHECIMENTO E A CONSTRUÇÃO DO MÉTODO DIALÉTICO COMO NOVO PARADIGMA DO DIREITO
}

\author{
COMMON SENSE TO SCIENCE: THE THEORY OF KNOWLEDGE AND THE \\ CONSTRUCTION OF THE DIALECTICAL METHOD AS NEW PARADIGM OF \\ THE LAW
}

\author{
${ }^{1}$ Emetério Silva de Oliveira Neto \\ ${ }^{2}$ Igor Moura Rodrigues Teixeira
}

\begin{abstract}
RESUMO
O presente trabalho tem por intuito analisar a problemática que envolve dois conceitos iniciais ao estudo da Teoria do Conhecimento, são eles o senso comum e a ciência. A partir desta análise inicial, verificar-se-á a confluência destes dois métodos como uma metodologia própria no processo de obtenção do conhecimento sob o prisma da análise sobre os obstáculos epistemológicos de Bachelard. Propõe-se, portanto, a superação dialética de determinados pressupostos trabalhados, haja vista que o conhecimento do mundo e das coisas, dos objetos ou entes, a forma originária pela qual se tem acesso a tais entes, consiste no trato mantido com eles na vida cotidiana. O cientista social deve construir seu conhecimento apesar e contra o senso comum, apesar e contra a realidade. Sob esse panorama, passa-se a analisar a epistemologia jurídica sob as suas formas tradicionais, os métodos empiristas e idealistas, a fim de estabelecer os mecanismos para o estudo do Direito proposto por elas e identificar que estas correntes encontram-se em objeto de superação por uma Teoria do Direito Contemporânea. Por fim, urge, em última instância, a proposição do método dialético como uma metodologia científica que dialogue com os elementos que compõem o Direito em todas as suas esferas, estabelecendo-se um elo constante com o que há de mais inerente aos destinatários da norma jurídica, as suas características históricas, sociais e políticas, atrelado a uma análise crítica da sociedade.
\end{abstract}

Palavras-chave: Ciência, Senso comum, Epistemologia jurídica, Método dialético

\footnotetext{
${ }^{1}$ Mestre em Direito pela Universidade Federal do Ceará - UFC, Fortaleza - CE (Brasil). Professor da Universidade Regional do Cariri - URCA, Crato - CE (Brasil). E-mail: emeteriodireito@ yahoo.com.br

${ }^{2}$ Mestre em Direito pela Universidade Federal do Ceará - UFC, Fortaleza - CE (Brasil). Professor da Faculdade Vale do Jaguaribe - FVJ, Caicó - RN (Brasil). E-mail: igormoura.r@gmail.com
} 


\begin{abstract}
This study is meant to examine the issue involving two initial concepts to the study of Theory of Knowledge, which are: common sense and science. From this initial analysis, will be checked the confluence of these two methods as a own methodology in the process of obtaining knowledge under the prism of the analysis of the epistemological obstacle of Bachelard. It is proposed, therefore, the dialectic overcoming of certain assumptions worked, given that knowledge of the world and things, objects or entities, the original form in which it has access to such entities, consisting in dealing maintained with them in life everyday. The social scientist must build their knowledge despite and against common sense, despite and against reality. Under this scenario, passes to examine the legal epistemology in its traditional forms, the empiricists and idealists methods in order to establish the mechanisms for the study of law proposed by them and identify that these currents are in fase of superation by a Contemporary Legal Theory. Finally, it is urgent, ultimately, the proposition of the dialectical method as a scientific methodology, which be capable of dialoguing with the elements that make up the law in all its spheres, setting up a constant link with what is more inherent to the recipients of the rule of law, its historical, social and political characteristics, linked to a critical analysis of society.
\end{abstract}

Keywords: Science, Common sense, Legal epistemology, Dialectical method 


\section{INTRODUÇÃO}

O trabalho terá como objeto de estudo os conceitos de ciência e senso comum, como ponto de partida para uma análise sobre a teoria do conhecimento contemporânea e o método a ser empregado para uma ciência própria ao Direito. Como se sabe, esses dois conceitos iniciais são duas modalidades distintas do conhecimento. Nesse sentido, buscar-se-á a possibilidade de relacionarem-se e, em caso positivo, quais as consequências - boas ou más, exequíveis ou inexequíveis - daí advenientes.

Para tanto, algumas análises iniciais serão procedidas. A primeira delas diz respeito ao estudo da teoria geral do conhecimento, que envolve a interpretação e explicação filosófica do conhecimento humano, em síntese a estruturação do conhecimento, o modo pelo qual ele é apreendido, com influxos em todas as modalidades do saber.

Estabelecida uma análise geral, passa-se ao conceito de ciência e à distinção, a título comparativo e ilustrativo, entre esta e outras formas de conhecimento, como o filosófico e o religioso ${ }^{1}$. Em seguida, à definição do conceito de senso comum e sua aplicação, bem como algumas investigações sobre se este conhecimento é tributário de importância hodiernamente.

À luz das delimitações conceituais empreendidas, a questão nodal que se colocará será a de se saber se é viável ou possível haver relações entre tais espécies de conhecimento, sempre na busca por respostas às mais candentes perguntas que envolvem o ser humano e sua existência ${ }^{2}$.

A posteriori, analisar-se-á a busca de uma superação das antinomias porventura existentes entre essas espécies de conhecimento, o que se fará por meio de uma dialética que reconheça os pontos positivos de cada um e, por conseguinte, a integração entre eles e não uma "incomensurabilidade" - ideia de paradigma de Thomas Khun (2005) - ou "corte epistemológico" - Gaston Bachelard (1972) -, pois como diz Boaventura de Sousa Santos (2009, p. 55), a ciência, na pós-modernidade, sabe que nenhuma forma de conhecimento é racional em si mesma, mas só a configuração de todas elas é racional.

\footnotetext{
1 Este será analisado apenas pontualmente.

2 Essas perguntas almejam a fundamentação ontológica do conhecimento, dos seres e das coisas.
} 
Por fim, o trabalho visa realizar uma análise sobre as metodologias empregadas tradicionalmente para se desenvolver uma ciência própria ao Direito. Uma discussão de cunho eminentemente epistemológico que se refere a reflexões sobre a própria estrutura e métodos de aplicação do sistema jurídico. Para tanto, parte-se de um levantamento inicial e introdutório das duas macro escolas de epistemologia jurídica, sob as quais se enquadram as metodologias específicas delineadas por diversos autores da ciência jurídica, são elas: as escolas idealistas e empiristas.

Não obstante, procurar-se-á um método alternativo a essas duas macro escolas, no sentido de fornecer à ciência jurídica uma metodologia própria de análise científica, atenta aos elementos que o compõem. Vislumbra-se a concepção da estruturação de uma ciência própria do Direito como sistema aberto, plural e garantista de direitos, com eficácia e vigência social efetivas.

Ressaltando-se do panorama hodierno a perspectiva pós-positivista e neoconstitucionalista que denota a superação de um olhar conservador e dogmático à ciência jurídica, o que remete ao cientista do direito a necessidade de um olhar sobre teoria do direito mais próxima dos anseios sociais e políticos enfrentados pelas sociedades contemporâneas.

As mudanças avultadas por este trabalho encontram-se atreladas a este novo olhar decorrente de um contexto de revolução paradigmática do direito, em transformação desde a Segunda Grande Guerra e que se substancia a cada dia na práxis cotidiana das instituições jurídicas. Desta forma, em um primeiro momento, procurar-se-á expor, em linhas gerais, o modelo dialético a ser adotado como esta nova perspectiva para a ciência jurídica, frente aos métodos tradicionais estabelecidos, que, por vezes, corroboram para um exacerbado dogmatismo ou em um abstrativismo sem aplicabilidade social.

\section{ANÁLISE GERAL DA TEORIA DO CONHECIMENTO}

A teoria do conhecimento se tornou disciplina filosófica independente na Idade Moderna a partir de John Locke, com a obra "An Essay Concerning Human Understanding” (apud HESSEN, 2012, p. 14). Na filosofia continental, através do contributo de Kant, com a obra “A Crítica da Razão Pura” (apud HESSEN, 2012, p. 15), de 1781, onde tematizou o método transcendental e o criticismo. 
A teoria geral do conhecimento tem por fito precípuo interpretar e explicar filosoficamente o conhecimento humano. Nesta senda, alguns métodos são utilizados, dentre eles o método fenomenológico, que busca apreender a essência geral, ou seja, aquilo que é essencial a todo conhecimento, no fenômeno concreto.

Para o método fenomenológico, o fenômeno do conhecimento se apresenta do seguinte modo: consciência (sujeito) e objeto. Ou seja, o conhecimento é a relação (ou dualismo) entre sujeito e objeto (essência do conhecimento), mediada pela consciência daquele. Contudo, nessa relação, sujeito e objeto permanecem eternamente separados, cada qual na dimensão que lhe é própria, pois o sujeito é completamente diverso do objeto.

Ressalta-se, porém, que ao mesmo tempo essa é uma relação recíproca (é correlação): o sujeito só é sujeito para um objeto e o objeto só é objeto para um sujeito (HESSEN, 2012, p. 20).

A função do sujeito é apreender o objeto e a função do objeto é a de ser apreensível e apreendido pelo sujeito. O sujeito invade a esfera do objeto, porém o objeto não é arrastado para a esfera do sujeito. $\mathrm{O}$ objeto permanece transcendente ao sujeito. Não há alteração no objeto. $\mathrm{O}$ que há é alteração no sujeito, provocada pela função cognoscitiva. Surge, assim, no sujeito uma figura ou imagem (as determinações se alastram no sujeito) do objeto. $\mathrm{O}$ objeto tem preponderância sobre o sujeito. O objeto é o determinante e o sujeito é o determinado.

Assim, o conhecimento pode ser definido como uma "determinação do sujeito pelo objeto". Sendo a imagem no sujeito que "sofre" a determinação do objeto o meio com o qual a consciência cognoscente apreende seu objeto.

Mas essa receptividade do sujeito com respeito ao objeto não significa passividade. Isso porque a consciência pode ter uma participação criadora na imagem do objeto. $\mathrm{O}$ conhecimento visa um objeto independente da consciência cognoscente (receptividade), o que não exclui a espontaneidade (âmbito da imagem). O "ser em si do objeto" consiste naquilo que ainda é desconhecido; o "ser em si do sujeito" consiste naquilo que ele é além de sujeito que conhece. Resulta que no interior do conhecimento a relação ou correlação entre sujeito e objeto é indissolúvel e não reversível. Na ação, porém, o sujeito determina o objeto, que se comporta passivamente. 


\section{O QUE É CIÊNCIA}

Entre as funções superiores do espírito e da cultura incluem-se a ciência e a religião. A religião é expressão cultural, de modo que é inegavelmente conhecimento ${ }^{3}$. A filosofia, conhecida como a ciência das ciências, pertence completamente ao âmbito teórico do espírito humano. Assim, a filosofia se coloca nas cercanias da ciência, eis que filosofia e ciência estão baseadas no pensamento (HESSEN, 2012).

Mas qual seria a diferença entre filosofia e ciência? Distinguem-se por seu objeto. As ciências particulares tomam por objeto uma parte da realidade, ao passo que a filosofia dirigese à totalidade do real. A filosofia, assim, é a ciência do universal.

As ciências stricto senso buscam um saber objetal (a pergunta é: “o que é?”). A filosofia, ao contrário, um saber transcendental, de legitimação (a pergunta muda, passando a ser: “como os objetos nos são dados?”) e o saber é reflexivo; é a teoria das estruturas fundamentais.

Existe uma profunda afinidade entre filosofia e religião (domínios culturais), pois estão ligados por seu objeto, que são os mesmos enigmas do mundo e da vida. Os dois buscam, no fundo, solucionarem tais enigmas, ou seja, fornecerem uma interpretação da realidade, uma visão de mundo. (HESSEN, 2012)

Portanto, a filosofia tem em comum com a religião o olhar dirigido à totalidade do real e com a ciência o caráter teórico. De modo que filosofia, ciência e religião iluminam aspectos da realidade. Enquanto reflexão sobre o comportamento teórico, a saber, sobre a ciência, a filosofia é teoria do conhecimento científico (teoria da ciência).

A tarefa primordial da ciência é delinear os fenômenos e ordenar em série os acontecimentos decisivos de uma experiência. Algumas etapas históricas do pensamento científico são: 1) o estado pré-científico (antiguidade clássica, renascimento, séculos XVI, XVII e XVIII); 2) o estado científico (fim do século XVIII, século XIX inteiro e início do século XX); e o 3) novo espírito científico (ano de 1905, a par da relatividade de Einstein) (BACHELARD, 1996).

\footnotetext{
3 Supedaneada na fé embora, não deixa a religião de ser importante veículo de conhecimento. Entende-se não ser a religião conhecimento racional porquanto se afigura insuscetível de comprovação empírica, v.g., as parábolas bíblicas, que muitos acreditam que aconteceram ou que ainda haverão de acontecer. Tal crença, no entanto, não pode ser comprovada por a mais $b$.
} 
Só os eixos racionais permitem a construção do conhecimento científico, sendo que todo saber científico deve ser reconstruído a cada momento. Mas o lado psicológico do homem influiria no conhecimento científico? Em qualquer questão ou fenômeno há a via psicológica do pensamento científico: o estado concreto, caracterizado pelas primeiras imagens dos fenômenos e exaltação da natureza; o estado concreto-abstrato, que acrescenta à experiência física esquemas geométricos, sendo a intuição sensível; e o estado abstrato, no qual há informações voluntariamente subtraídas à intuição do espaço real.

Há entendimentos resistentes segundo os quais a experiência científica contradiz a experiência comum, pois de nada serve a experiência que não retifica nenhum erro, que é monotonamente verdadeira e sem discussão (BACHELARD, 1996). O pensamento científico é calcado na perspectiva de "erros retificados".

As afirmações científicas são meras estimativas, possíveis de verificação e falsificação. As palavras de Nicholas Rescher (2003, p. 32), a respeito da provisoriedade do conhecimento científico, são esclarecedoras:

\begin{abstract}
Scientific knowledge at the level of deep theory is always purported knowledge: knowledge as we see it today. In our heart of hearts, we realize that we may see it differently tomorrow - or the day after. We must stand ready to acknowledge the fragility of our scientific theorizing. All we are ever able to do in natural science is to select the optimal answer to the questions we manage to formulate within the real in of alternatives specifiable by means of the conceptual machinery of the day. And we have no reason to doubt - nay, we have every reason to believe - that the day will come when this conceptual basis will be abandoned, in the light of yet unrealizable developments, as altogether inadequate.
\end{abstract}

O professor Hugo Segundo (2008, p. 14), sobre o conhecimento científico bem lembra que hoje se entende que a ciência é essencialmente provisória, composta de teorias e enunciados considerados verdadeiros até que se demonstre o contrário.

Esse é o caminho palmilhado por Karl Popper (2010, p. 102) para quem uma teoria científica é aceita apenas e tão-somente enquanto resiste aos mais severos testes contra ela desferidos. Dessarte, dia haverá em que essa resistência não mais subsistirá e a teoria antiga sucumbirá ante a nova e assim por diante.

Para Bachelard, o conhecimento científico se constitui rompendo com o conhecimento comum. Numa palavra, não há aprimoramento ou continuidade. Destarte, é com o objeto de conhecimento (objeto construído) e não diretamente com o objeto real, que efetivamente trabalham as ciências. Para a ciência, "o verdadeiro é o retificado, aquilo que por 
ela foi feito verdadeiro". As teorias científicas resultam sempre de um processo de construção, onde a razão tem papel ativo.

\title{
4 O QUE É SENSO COMUM?
}

Immanuel Kant (2001), logo no início da introdução de sua obra “A crítica da razão pura", pontifica não restar dúvida de que todo o conhecimento humano começa pela experiência ${ }^{4}$. É o que se colhe do seguinte relanço:

\begin{abstract}
Efetivamente, que outra coisa poderia despertar e pôr em ação a nossa capacidade de conhecer senão os objetos que afetam os sentidos e que, por um lado, originam por si mesmos as representações e, por outro lado, põem em movimento a nossa faculdade intelectual e levam-na a compará-las, ligá-las ou separá-las, transformando assim a matéria bruta das impressões sensíveis num conhecimento que se denomina experiência? Assim, na ordem do tempo, nenhum conhecimento precede em nós a experiência e é com esta que todo o conhecimento tem o seu início.
\end{abstract}

Conforme visto, o conhecimento científico é conhecimento eminentemente teórico e racional e o filosófico tem a pretensão de universalidade. Já o senso comum é conhecimento empírico e assistemático, pois ocorre no dia a dia de modo espontâneo.

Para Popper (2010, 217-222) está intimamente ligado ao realismo, sendo indemonstrável e irrefutável, não podendo ser testado, razão pela qual é chamado de realismo metafísico.

Assim, o senso comum é aquele tipo de conhecimento eminentemente prático e assistemático que rege a maior parte de nossas ações diárias (MARQUES NETO, 2001). É de um consenso de opiniões que o conhecimento comum retira sua veracidade. Tem como nota característica o empirismo (caráter eminentemente prático), diferentemente da ciência que se notabiliza, conforme debatido, pela sistematicidade, controle e rigor.

O senso comum, pois, constitui pura e simples captação da realidade, sendo o conhecimento científico mais elaborado e sofisticado. Constitui-se sobre a base da opinião e nele não há elaboração intelectual sólida, porquanto é assistemático, sem nexo com outros conhecimentos e "ambíguo", pois reúne sob o mesmo nome e numa mesma explicação conceitos diferentes, em detrimento do rigor metodológico próprio da ciência.

\footnotetext{
4 Isso não quer dizer, como afirma o próprio Kant, que todo ele deriva da experiência (a posteriori). Com efeito, Kant dividiu o conhecimento humano em duas categorias, a saber: analíticas e sintéticas (juízos de experiência). As proposições analíticas, nas quais o predicado está contido no sujeito, determinam o conhecimento a priori. Assim, Kant também acreditava em um conhecimento prévio, a priori, adquirido sem a necessidade da experiência, afirmando ser ele uma parte essencial do conhecimento.
} 
Por isso, o conhecimento comum, produzido no bojo da sociedade, de forma assimétrica, mas com a naturalidade do ser cognoscente por excelência, o homem, tende a contribuir com um processo de mudança paradigmática. Pois traz, em si, um olhar despretensioso sobre a sistematização de uma determinada teoria para a resolução do problema posto. Coloca um posicionamento bruto, mas que se pode retirar a essência da vontade social sobre o problema que se busca resolver, portanto, não deve descartado e sim aproveitado a título de objeto de lapidação pelos cientistas e teóricos.

O senso comum parte do real ou do "dado". No que concerne às teorias científicas, vê-se que é para o real que em última instância elas se dirigem. Nunca esquecer, entrementes, que a captação do real jamais é pura, de vez que ela é obtida através de um método e, assim, se todo dado é construído, infere-se que toda teoria científica se caracteriza por expressar um conhecimento aproximado, retificável, e não um simples reflexo dos fatos.

O ponto de partida de toda investigação científica é muito mais teórico de que real, e aqui repousa a diferença fulcral entre os tipos de conhecimento estudados.

\section{POSSÍVEIS RELAÇÕES ENTRE AMBOS E A IDEIA DE “CORTE EPISTEMOLÓGICO” DE BACHELARD}

Com efeito, a realidade não apresenta problema algum. Ao contrário, ela é problematizada e explicada. Assim, a primeira conclusão é a de que o conhecimento científico se constitui e se desenvolve contra as evidências confirmadas pelos fatos. Por exemplo, as teorias de Issac Newton e as noções euclidianas de tempo e de espaço foram consideradas irretocáveis até mesmo por Kant, mas Einstein, contudo, utilizando conceitos geométricos não euclidianos, revolucionou com a noção relativista de tempo-espaço, chocando frontalmente com as evidências do senso comum. A teoria de Einstein não se constituiu do contato com os fatos. Para a elaboração da teoria da relatividade restrita (1905) e da teoria geral da relatividade (1916), Einstein utilizou conceitos teóricos das geometrias não euclidianas, tendo elaborado seu sistema de explicação no plano da teoria, sem maiores contatos com os fatos. Trabalhou sobre o construído e não sobre o dado. As primeiras comprovações empíricas de suas teorias só ocorreram após a publicação dessas teorias.

O conhecimento científico não constitui simples cópia do real - ainda que sofisticada 
-, mas uma assimilação deste às estruturas teóricas que sobre ele agem e o transformam. O conhecimento científico não é contemplativo, ele é operativo. É antes aproximado que verdadeiro. É processo sempre inacabado, pois para Popper a ciência não traz a verdade, mas a aproximação desta (o que hoje é aceito pode vir a ser falseado amanhã).

A questão que se coloca é a de provar se realmente há esta independência entre o construto científico e o real, ou seja, se de fato essa problematização sobre a realidade é pura.

Nesse propósito, Gaston Bachelard desenvolveu a noção de obstáculo epistemológico. Para ele, aceder à ciência é rejuvenescer espiritualmente, é aceitar uma brusca mutação que contradiz o passado.

Corte epistemológico, para Gaston Bachelard, designa e explica, numa palavra, as ruturas ou as mudanças súbitas que acontecem ao longo do processo de evolução do conhecimento científico na busca de uma crescente objetividade, em que o racional, que é construído, se vai sobrepondo num esforço constante ao consciencial, que é meramente subjetivo.

A evolução do conhecimento científico, afirma Bachelard, é descontínua e acontece por oposição aos sistemas anteriores, numa procura de ultrapassar os obstáculos epistemológicos que neles se patenteiam. Ocorre, assim, quando uma nova teoria não apenas rompe com a teoria anterior e com o problema por ela formulado, mas também com todo o sistema de explicações contido no conhecimento acumulado retificando-o profundamente e acrescentando-se a ele por descontinuidade, limitando-o e abrindo consequentemente um espaço teórico inteiramente novo dentro da ciência.

É sob este prisma, que se propõe repensar um método próprio para ciência jurídica, que ultrapasse a barreira do dogmatismo jurídico e coloque a busca e a produção do conhecimento do direito em estradas não antes percorridas pelos modelos epistemológicos tradicionais.

Para sustentar as suas articulações teóricas, Bachelard cita dois exemplos de obstáculos epistemológicos: 1) o obstáculo da realidade, onde o pesquisador ao olhar seu objeto de estudo pode incorrer no perigo de se deixar levar pelo que lhe é visível, dando a este um estatuto de verdade que ele não tem. A realidade nada responde por si mesma, mas somente o faz através de questões levantadas teoricamente; 2) obstáculo do senso comum (opinião), representada pelos preconceitos, as avaliações relacionadas a posição social e econômica.

O cientista social deve construir seu conhecimento apesar e contra o senso comum, apesar e contra a realidade. Deve-se ressaltar que as ciências sociais, precipuamente, denotam um olhar sobre um fenômeno em constante mutação, a sociedade, e os vários elementos que o 
compõem. Portanto, ipso facto, que isso aponta para um olhar questionador sobre tais elementos e o todo social. As conclusões/soluções apresentadas devem estar em constante revisão de seus pressupostos.

Para Bachelard, a partir da ideia de novo espírito científico, o conhecimento científico encontra-se em descontinuidade/ruptura com o senso comum (seria o que Thomas Kuhn apoda de incomensurabilidade de paradigmas). Isso implica em distinção entre o universo do senso comum (onde se localizam as opiniões e os preconceitos) e o universo das ciências.

A marca de Bachelard é a "ruptura epistemológica" entre a ciência contemporânea e o senso comum. Assim, o conhecimento científico é construído através da constante análise dos erros anteriores. Com efeito, Bachelard combateu o continuísmo, que defendia a ideia segundo a qual entre ciência e senso comum não existia mais que uma diferença de profundidade ou uma continuidade epistemológica.

Em Bachelard há uma superação do empirismo (conhecimento comum ou senso comum) pelo racionalismo (conhecimento científico), em que este nada tira de proveitoso ou aproveitável daquele ${ }^{5}$.

Destarte, a ideia de ruptura prega que entre conhecimento científico e senso comum não pode haver pontos de contato. O presente trabalho, contudo, busca encontrar os fios condutores que possibilitem o contato de alguns pontos destes ramos do saber.

Outro ponto relevante, segundo os atores, é que a ciência opõe-se à opinião, de tal maneira que se vier a legitimá-la é por motivos diversos daqueles que lhe deram origem. Sob este prisma, a opinião está sempre errada, pois não pensa ou pensa mal, e o que faz é traduzir necessidades em conhecimentos. O conhecimento científico, ao revés, é resposta a uma pergunta e nele nada é evidente ou gratuito, mas tudo é construído. A pergunta abstrata se desgasta, mas a resposta correta fica.

Nunca é demasiado lembrar que as teorias científicas existem para serem aplicadas e ipso facto trazerem benefícios práticos à sociedade. As ciências são um produto social. De modo que teoria e prática são complementares ao conhecimento científico.

\footnotetext{
5 De acordo com Chalmers, uma característica-chave da teoria de T. Khun é a ênfase dada ao caráter revolucionário do progresso científico, em que uma revolução implica o abandono de uma estrutura teórica e sua substituição por outra, incompatível. Ainda segundo Chalmers, outro traço essencial é o importante papel desempenhado na teoria de Kuhn pelas características sociológicas das comunidades científicas (CHALMERS, 1993, p. 111).
} 
Conforme dito alhures, a ciência, nos tempos pós-modernos, busca dialogar com outras formas de conhecimento, mormente com o senso comum, deixando-se penetrar por elas (SANTOS, 2009, p. 55) ${ }^{6}$.

Paul Feyerabend (2011, p. 97) adverte que há sociedades, como a da China Continental, em que procedimentos tradicionais são combinados com ideias científicas, levando a uma melhor compreensão da natureza e a um tratamento melhor das disfunções individual e social.

A teoria precisa ter utilidade e a possibilidade da sua aplicação prática evita que seja vazia de sentido. Por outro lado, prática sem conhecimento teórico é uma prática cega, assistemática, fortuita e ineficaz. Defende-se, pois, que não existe separação, nem muito menos irreconciliação entre teoria (entendida aqui como conhecimento científico) e prática (entendida aqui como senso comum). O que há é distinção.

Portanto, não há que se falar em incomensurabilidade entre ciência e senso comum. Nesse diapasão, depreende-se das lições de Hugo Segundo (2008, p. 13) que "quando se perquire a respeito de ciência, cogita-se de uma espécie ou modalidade do conhecimento humano, que pode decorrer simplesmente do senso comum, sendo chamado conhecimento comum, ou pode ser científico". Deste modo, o conhecimento científico pode sim derivar do senso comum e nada obsta que este seja corroborado pelo primeiro.

\section{O RESULTADO DE UMA DIALÉTICA SUPERADORA}

Avulta inegável que todo o conhecimento, não importa de que "modalidade" se trate, por regra é materializado nas relações que as pessoas entretêm entre si, de modo que só faz sentido a partir de sua referibilidade aos sujeitos.

Enrique Aftalión, José Vilanova e Julio Raffo trabalham o conhecimento na vida cotidiana. Os autores defendem a corrente da fenomenologia existencial. Numa palavra, afirmam que o que leva ao conhecimento do mundo e das coisas, dos objetos ou entes, a forma originária pela qual se tem acesso a tais entes, consiste no trato mantido com eles na vida cotidiana.

\footnotetext{
6 o referido autor afirma, na mesma passagem, que a ciência moderna, hoje ultrapassada, construiu-se contra o senso comum, o qual considerou "superficial, ilusório e falso".
} 
Com efeito, a aproximação do conhecimento desde a perspectiva do homem comum e sua vida cotidiana permite o exercício da capacidade crítica por parte do estudante, pois é das situações cotidianas que ele pode controlar as generalizações, abstrações e construções próprias de todo conhecimento (AFTALIÓN; VILANOVA; RAFOO, 2004). Esse conhecimento é o que se encontra implícito na conduta do homem. Para Aftalión é a practognosis (ação/conhecimento), ou seja, um saber que se encontra implícito na ação e explícito em palavras (opinião).

O conhecimento da vida cotidiana revela o mundo familiar, que está rodeado por uma zona de penumbra (ignorância), que de seu turno está rodeada pelo desconhecido (não há saber algum). Segundo Aftalión, todo conhecimento practognótico de alguma maneira compreende habilidades (o autor explica como essas habilidades são adquiridas).

A verdade não constitui uma possessão segura do conhecimento, senão que é aquilo a que o conhecimento aspira. O homem no ato de conhecer trata com o desconhecido. O conhecimento é uma atitude e não um conjunto de proposições ou enunciados verdadeiros.

Para os autores, "a atitude aberta ao conhecimento significa que de algum modo se aceita a existência do desconhecido, que há algo que não se conhece, atitude que é o ponto de partida do conhecer" (AFTALIÓN; VILANOVA; RAFOO, 2004).

Em suma, o saber espontâneo do homem comum consiste em: mundo familiar; penumbra; desconhecido. Eis uma ilustração dos autores: $1^{\text {a }}$ ) o camponês (labriego) - o homem, por mais ignorante que seja, sabe muitas coisas, e esse saber o faz atuar com certa eficácia; esse é saber do mundo familiar, mas esse mundo familiar está rodeado de uma zona de penumbra (o saber sobre essa zona de penumbra não tem a precisão nem a consistência que tem a familiaridade com seu mundo cotidiano), e esta zona de penumbra está rodeada por uma zona onde não há nenhum saber (total obscuridade, ou seja, há coisas sob as quais não tem referência e sob as quais sequer imaginou). Assim, há no conhecimento comum uma zona bem iluminada (o mundo familiar bem conhecido), seguida de uma zona de penumbra (o vagamente conhecido), todo ele imerso numa zona sem limites de obscuridade total (o desconhecido). É aqui que entra a imprescindibilidade do conhecimento científico, o que por vezes serve para desvendar a chamada "zona de penumbra".

A opinião não é um saber que se revela na ação, mas pode ser redondamente falsa ou redondamente verdadeira e possui função descritiva. Já a experiência comum não é construída, eis que é feita de observações justapostas. De modo que não pode ser verificada e permanece um fato. Assim, não pode criar uma lei. Porém, verdades de fato conseguem integrar- 
se de imediato na ciência, e aqui está o principal ponto de contato entre esses conhecimentos.

Ora, se nem mesmo a ciência, que usa métodos eminentemente racionais, tem condições de desenvolver um conhecimento verdadeiro, conforme delineia Popper, senão apenas momentaneamente aceitável pela comunidade científica, por que criticar a "irracionalidade" do senso comum? Este, malgrado produzido assistematicamente, tem os seus acertos (muitos momentâneos, tal qual a ciência) e deste modo pode perfeitamente integrarse ao conhecimento científico, produzindo-se um "saber unificado".

O mais importante resultado da dialética ou do intercambiamento entre conhecimento científico e senso comum é o enriquecimento que tal processo proporciona no que diz respeito às relações dos seres humanos com o mundo. Segundo Boaventura (2009, p. $56)$,

\begin{abstract}
É certo que o conhecimento do senso comum tende a ser um conhecimento mistificado e mistificador mas, apesar disso e apesar de ser conservador, tem uma dimensão utópica e libertadora que pode ser ampliada através do diálogo com o conhecimento científico. Essa dimensão aflora em algumas das características do conhecimento do senso comum. ${ }^{7}$
\end{abstract}

Por derradeiro, é de bom alvitre ressaltar que Álvaro Cruz (2009, p. 150), evocando lúcido questionamento de Watkins, elaborado a partir da análise das teorias de K. Popper e T. Khun, pergunta se não seria exatamente o excesso de pesquisas empíricas o que promoveria o avanço da ciência normal.

O que se propõe, portanto, é uma mudança de perspectiva sobre a produção do conhecimento, em um primeiro momento, e o desenvolvimento de novos métodos para se elaborar uma teoria do conhecimento válida hodiernamente, em seguida. O modelo dialético, em seu aspecto geral, procurar unir elementos antes contrapostos, mas que hoje podem ser vislumbrados como vias de comunicação dupla e real na produção de novos paradigmas. É sob esta assertiva que se desenvolve o próximo capítulo, a partir desse novo olhar, procurar- seá o aporte crítico necessário ao desenvolvimento de modelo epistemológico para o Direito, através do panorama dialético.

\footnotetext{
7 No mesmo trecho o autor, em discurso laudatório sobre o senso comum, pontifica: "o senso comum é prático e pragmático; reproduz-se colado às trajectórias e às experiências de vida de um dado grupo social e nessa correspondência se afirma fiável e securizante. O senso comum é transparente e evidente; desconfia da opacidade dos objectivos tecnológicos e do esoterismo do conhecimento em nome do princípio da igualdade do acesso ao discurso, à competência cognitiva e à competência linguística. O senso comum é superficial porque desdenha das estruturas que estão para além da consciência, mas, por isso mesmo, é exímio em captar a profundidade horizontal das relações conscientes entre pessoas e entre pessoas e coisas. O senso comum é interdisciplinar e imetódico; não resulta de uma prática especificamente orientada para o produzir; reproduz-se espontaneamente no suceder quotidiano da vida. O senso comum aceita o que existe tal como existe; privilegia a acção que não produza rupturas significativas no real. Por último, o senso comum é retórico e metafórico; não ensina, persuade".
} 


\title{
7 A CRÍTCA AOS MÉTODOS TRADICIONAIS DE CIÊNCIA DO DIREITO E O MÉTODO DIALÉTICO COMO NOVO PARADIGMA
}

A ciência jurídica tem passado por diversas críticas, tais abordagens se acentuam, haja vista o grande emaranhado de teorias para se explicar a ciência e a aplicação do direito que se encontram destoantes com os anseios de sua aplicabilidade prática na sociedade. Desta forma, os juristas, os aplicadores e os cientistas do direito em geral devem desenvolver instrumentos de comunicação entre os elementos que compõem o direito, remetendo-se, superficialmente, aos elementos formatados por Miguel Reale - fato, valor e norma - e uma ciência que busca a devida compreensão destes fenômenos.

Partindo dessa ideia inicial, critica-se a forma do direito, em um primeiro plano, como direito supra-social, correspondente a uma ordem divina ou natural, em que, a norma jurídica seria a sua expressão imperfeita; e, em um segundo momento, o formato de equivalência entre direito e norma, que implica na suposição de que ambos constituem uma só realidade e na consequente negação da existência, no interior de um espaço-tempo social, de fenômenos que possam ser investigados sob o enfoque jurídico.

A crítica em questão é formatada devido ao hábito cientifico de aproximação entre as ciências humanas, ou sociais, como se verifica ao percorrer do estudo, das ciências da natureza, que incorre em uma problemática metodológica em gênese. Isso ocorre, pois se deveria ter em mente os objetos da ciência do direito em uma relação permanente com os elementos sociais, históricos e culturais que compõem as mais variadas relações objetos do sistema jurídico.

Para Marques Neto (2001), essa visão afastada das características atinentes ao Direito em substrato é representada pela inadequação dos paradigmas do Direito natural e do Direito Positivo para a edificação de uma Teoria Científica do Direito. Conforme assevera,

\begin{abstract}
Ambos esses pontos de vista nos parecem inadequados a um estudo científico do Direito, o primeiro em razão de seu caráter essencialmente idealista e metafísico, que reduz o Direito a um capítulo da Religião, da Filosofia ou da Ética, somente acessível através da razão prática, para usarmos a expressão de KANT, e o segundo porque atribui à ciência do Direito, como exclusivo, um objeto de tal modo contingente e variável, que praticamente impossibilita a elaboração de teorias jurídicas de caráter científico, restringindo-as, no mais das vezes, a proposições de cunho hermenêutico sobre institutos e regras do Direito Positivo. (MARQUES NETO, 2001, p. 128)
\end{abstract}

Desta feita, propõe como alternativa às correntes clássicas, sob comento, uma metodologia dialética para a epistemologia jurídica, que tenha como base alguns pressupostos 
básicos, que, em síntese, procuram estabelecer que "a dialética estuda o Direito dentro do processo histórico em que ele surge e se transforma, e não a partir de concepções metafísicas formuladas a priori” (MARQUES NETO, 2001, p. 131).

Outro autor que trabalha com o método dialético é Lyra Filho, que procura desenvolver uma "visão social do direito", ou melhor, "um direito humanizador", relacionado à ideia de justiça social que se estabelece pela "própria libertação alcançada por meio de um processo histórico. [...] uma metodologia dialética para a apreensão do direito como um fenômeno da sociedade para a libertação e para a justiça social” (RODRIGUES; GRUBBA, 2013, p. 32).

Deste mesmo modo, Lyra Filho propõe a metodologia dialética com o fito deste superar a metafísica, não no sentido de negá-la, mas de complementá-la, ou melhor, transcendê-la, pois, para ele, a metafísica "não representava uma idealização, e sim uma lógica material, a lógica material por excelência, a que absorve e reenquadra os 'conflitos', assim como toda e qualquer contradição" (1993, p. 53). É nesse mote que se estabelece a utilização do método dialético, que parte de um olhar sob o curso da história como desenvolvimento e processo de conquistas sociais, na superação constante das relações de exploração tradicionalmente estabelecidas e, por vezes, reafirmadas pelo direito, para configurar uma nova metafísica. Trabalha-se, portanto, com uma ciência do direito que vise à emancipação, que encontrará abrigo, apenas em uma estrutura dialogal.

Torna-se relevante a presente discussão, no que tange a uma perspectiva dialética de ciência do direito, que forneça uma metodologia própria e atenta às perspectivas históricas e sociais das sociedades contemporâneas, caracterizadas, essencialmente, pela sua pluralidade. Deve-se delinear que

A dialética vê na ciência do Direito, não uma simples cópia, de qualquer realidade, mas um sistema construído de proposições teóricas, que, voltado para o real, o faz seu, assimilando-o e transformando-o, e, por isso mesmo, construindo-o e retificandoo. Esse sistema teórico se caracteriza como jurídico, não em decorrência do objeto tomado isoladamente, mas dos problemas específicos que a ciência do Direito se propõe, com vista a uma subsequente aplicação normativa. É só em função da teoria que comanda todo o processo de elaboração científica, que o objeto de conhecimento da ciência jurídica, assim como as normas que constituem sua parte técnica, podem fazer algum sentido. E as teorias da ciência do Direito como quaisquer teorias científicas, são essencialmente refutáveis e, por isso, carecem, não de ser afirmadas dogmaticamente, como o faz a maioria dos juristas, mas de ser questionadas, postas em xeque, como recomenda BACHELARD. É nesse sentido que o pensamento crítico se torna 'a lógica de uma teoria científica' (MARQUES NETO, 2001, p. 185-186).

Desse ponto de partida que se inicia a abordagem crítica sobre as correntes tradicionais que tratam da ciência do Direito. Mesmo com o advento do pós-positivismo como momento 
paradigmático de mudança no olhar sobre o Direito e a ciência jurídica, algumas das características entranhadas nas perspectivas empiristas e idealistas, conforme a classificação de Agostinho Ramalho Marques Neto (2001, p. 127-185), que se encontram em voga atualmente.

A título de esclarecimento, a correntes idealistas, para o autor em estudo, são aquelas escolas de pensamento jurídico-filosófico que, de alguma forma, estuda o direito desvinculandoo da ambiência social em que ele efetivamente se produz. É a perspectiva presa aos princípios apriorísticos e metafísicos, pois ignora, em substrato o caráter histórico- social do fenômeno jurídico e, consequentemente, se aliena das condições concretas em que ele surge nas diferentes sociedades. Dentre estas correntes, podem-se destacar o jusnaturalismo, que englobam desde as primeiras manifestações de ordem normativa de origem divina até à moderna concepção de Direito Natural; o criticismo kantiano, sob o qual se compreende a ideia que a liberdade constitui o fundamento essencial do Direito, pois duas ordens normativas regem a conduta humana, a moral e o direito ${ }^{8}$; o idealismo hegeliano, que compreende o Direito como "uma ideia eterna que se manifesta no desenvolvimento histórico do Direito Positivo" (MARQUES NETO, 2001, p. 138); e, por fim, o idealismo jurídico contemporâneo, correspondente às teorias pós Hegel e Kant que trabalham com a ideia de que determinados princípios jurídicos são desvinculados das condições espaço-tempo em que se desenvolve o Direito, abordando autores como Stammler. Gustav Radbruch; Luís Síches; Gioggio Del Vechio, dentre outros.

Já as correntes empiristas são aquelas que privilegiam o objeto da ciência jurídica, esquecendo, por vezes, a lição dialética de que é no processo relacional entre sujeito e objeto que o conhecimento se constrói. Apresentando-se, conforme assevera Marques Neto, em um obstáculo à epistemologia na elaboração de uma ciência eminentemente jurídica. Assim como o idealismo, o empirismo jurídico se caracteriza por adotar uma atitude metafísica diante do processo cognitivo.

\footnotetext{
8 Porém, o pensamento de Kant não distingue a Filosofia do Direito à ciência jurídica. Para ele não se pode compreender como ciência a simples aplicação de princípios racionais em si próprios.
} 
Dentre as escolas empiristas, destacam-se a escola da exegese; a escola histórica; escola sociológica; o dogmatismo normativista de Kelsen; e o egologismo existencial, de Cossio. As escolas em comento são apresentadas em determinados contextos históricos distintos e tem as suas características principais bem delineadas de acordo com cada perspectiva conjectural. Não se buscará neste estudo, portanto, realizar uma análise sobre todas as escolas empiristas, mas apenas referente ao dogmatismo normativista de Kelsen, devido a sua influência na dogmática jurídica contemporânea, bem como no sua estrutura como ciência jurídica.

Hans Kelsen coloca no centro de sua teoria a concepção de que as normas jurídicas são objeto da ciência do direito. Assim, conclui que a conduta humana só será enquadrada no mundo jurídico, na medida em que é determinada pela norma jurídica como pressuposto ou consequência. Para ele, "na medida em que apreende a conduta humana enquanto esta constitui conteúdo da norma jurídica, a ciência jurídica representa uma interpretação normativa destes fatos de conduta" (2003, p. 79).

De tal modo, distingue as normas jurídicas das proposições jurídicas. As primeiras são aquelas normas produzidas pelos órgãos jurídicos competentes para tal, a fim de por estes sejam aplicadas e observadas por seus destinatários. Já as proposições jurídicas são os juízos hipotéticos que enunciam ou traduzem, em conformidade com o sentido de uma ordem jurídica, em seus pressupostos, as consequências de determinadas ações e fatos, postos pelo próprio ordenamento.

Desta feita, cabe a assertiva de que a ciência jurídica tem por missão conhecer - de fora, por assim dizer - o Direito e descrevê-lo com base no seu conhecimento. Os órgãos jurídicos têm - como autoridade jurídica - antes de tudo, por missão produzir o direito para que ele possa então ser conhecido e descrito pela ciência jurídica. Os órgãos jurídicos, por sua vez, devem conhecer o direito por dentro e aplicá-lo. Trata-se, portanto, da função normativa da autoridade jurídica, caracterizada por ser prescritiva e volitiva; em contraposição com a função cognitiva da ciência jurídica, de caráter descritivo. ${ }^{9}$

\footnotetext{
9 Remete-se, ao meu ver, de certa forma, à teoria da "Moldura de Kelsen", sob a qual se estabelece que o cientista do direito ao analisar o sistema jurídico, sob o prisma de que esta ciência é pura, deve olhar apenas para o seu objeto, isto é, a norma jurídica, não relacionando à sua análise científica nenhum fator externo ao direito positivo. Entretanto, no momento de aplicação da norma, o aplicador não está preso ao que fora determinado pela moldura, pois este pode buscar elementos fora da moldura que fundamente a sua decisão. Devese, portanto, distinguir a interpretação do direito feito pela ciência jurídica, como não autêntica, da interpretação realizada pelos órgão jurídicos. A primeira é pura determinação cognoscitiva do sentido das normas jurídicas, encontrando-se adstrita aos limites da moldura, que, diferente da interpretação feita pelos órgãos jurídicos, não é criação jurídica. (KELSEN, 2003, p. 387-397)
} 
Aqui se depara com a problemática da teoria kelseniana, a qual, sob o estigma da pureza, encontra-se destoante com as características do estudo do direito contemporâneo, haja vista o caráter pluralista presente nas sociedades contemporâneas. A ciência do direito vista apenas como uma ciência descritiva aproxima-se de uma ciência da natureza, que na causalidade o método de compreensão científica mais adequada, diferentemente de como defende o autor, ao destacar o método da imputabilidade como característica à ciência jurídica.

Kelsen (2003, p. 86) limita o seu objeto a tal ponto, que afirma: "somente quando a sociedade é entendida como uma ordem normativa da conduta dos homens entre si é que ela pode ser concebida como um objeto diferente da ordem causal da natureza, só então é que a ciência social pode ser contraposta à ciência natural". Complementando, "somente na medida em que o Direito for uma ordem normativa da conduta dos homens entre si, pode ele, como fenômeno social, ser distinguido da natureza, e pode a ciência jurídica, como ciência social, ser separada da ciência da natureza".

Portanto, a confusão - conforme ressaltado por Kelsen - realizada por muitos autores, no que tange à utilização dos métodos da causalidade e da imputabilidade, é indevida. Explicita que "na proposição jurídica não se diz, como na lei natural, quando A é, B é, mas que, quando A é, B deve ser, mesmo quando B, por ventura, não seja” (2003, p. 87). Por conseguinte, isso seria o grande diferencial da norma jurídica para uma lei natural, isto é o caráter de normatividade do Direito que o coloca em um posicionamento diferenciado no que tange à metodologia científica.

Para Gadamer (2011, p. 449), “A crítica da razão pura de Kant justificou os elementos apriorísticos do conhecimento experimental das ciências da natureza. Assim convinha que se implementasse uma justificação teórica correspondente para o modo de conhecimento das ciências históricas.”, o que não fora devidamente desenvolvida pela teoria kelseniana. Nessa toada, que se estabelece que

[...] as diferentes epistemologias idealistas e empiristas assumem uma postura eminentemente acrítica, como que fetichizada, perante seus próprios princípios e asserções, deixando de submetê-los a um questionamento permanente e limitando-se a afirmá-los como se eles constituíssem autênticos dogmas de fé (MARQUES NETO, 2001, p. 179).

Desta forma, avulta-se a necessidade de uma análise ampla da ciência do direito, que corrobore pela construção de um método dialético que tem na figura da análise histórica a sua tese inicial. Sob esta perspectiva, que "o nexo histórico deve ser compreendido como um nexo 
de sentido que supera fundamentalmente o horizonte vivencial do indivíduo. É como um texto grande e estranho, para cuja decifração precisa da ajuda de uma hermenêutica." (GADAMER, 2011, p. 450).

Assim, na sua obra "Problemas epistemológicos das ciências humanas", Gadamer (2006, p. 19-20) complementa que

\begin{abstract}
De fato, a moderna metodologia de nossas ciências filológicas e históricas corresponde exatamente a essa concepção nietzschiana. Com efeito, ela pressupõe que o material com que tais ciências trabalham (fontes, vestígios de uma época passada) constitui-se de tal modo que requer uma interpretação crítica. Essa pressuposição desempenha papel decisivo e fundamental para as ciências modernas da vida histórica e social em geral. O diálogo que travamos com o passado nos coloca diante de uma situação fundamentalmente diferente da nossa - uma situação 'estranha', diríamos -, que consequentemente exige de nós um procedimento interpretativo.
\end{abstract}

Portanto, o ponto de partida para que represente um avanço na construção de uma ciência jurídica que tenha com um caráter emancipatório em sua dimensão objetiva, no sentido de garantista de direitos de forma equânime, é através, primeiro, da reconstrução de identidade, sobre as deficiências existentes e os avanços já alcançados, no âmbito do conhecimento histórico; em um segundo momento, através de um método que proporcione o real diálogo entre todos os elementos que compõem o direito, seja no seu aspecto eminentemente jurídico, remetendo-se ao positivismo, seja nos seus aspectos, sociais, políticos, econômicos e culturais. Todo esse processo de construção passa pelo diálogo, pois

\footnotetext{
A identidade do eu, assim como a identidade do sentido, que se constrói através dos participantes do diálogo, permanece intocada. É evidente que nenhuma compreensão de um pelo outro dialogante consegue abranger todo o âmbito do compreendido. [...] Quando dizemos que nos entendemos sobre alguma coisa, isso não significa, em absoluto, que um tenha uma opinião idêntica ao outro. 'Chega-se a um acordo', como diz muito bem a expressão (GADAMER, 2011, p. 25).
}

Portanto, diante do que se pretende de um novo paradigma da ciência do Direito, que aponte para a eficácia de suas normas e que acompanhe as constantes transformações perpassadas pela sociedade, o diálogo é o elemento central. O desafio para o cientista é desenvolver estes elos de comunicação, trata-se de um de "des-pensar", utilizando-se de um termo de Santos (2011, p. 186), que por si só é “[...] uma tarefa epistemologicamente complexa porque implica uma desconstrução total, mas não niilista, e uma reconstrução 
descontínua, mas não arbitrária. [...] o processo de des-pensar equivale a uma nova síntese cultural".

Por fim, ao referenciar que apenas o método dialético, apartando-se as amarras adstritas aos modelos tradicionais, como instrumentos de uma ciência jurídica que proporcione a análise do Direito sob o viés de sua eficácia e real aplicabilidade às relações sociais, Marques Neto (2001, p. 220) leciona:

A ciência do Direito, tanto em seus momentos teóricos como práticos, deve, por conseguinte, acompanhar a dinâmica social, condicionando-a e sendo por ela condicionada, num verdadeiro relacionamento dialético. Aliás, não podemos considerar como válido nenhum critério de eficácia das leis, senão o seu confronto com as proposições da ciência do Direito e principalmente a sua adequação às reais necessidades e aspirações das bases sociais.

\section{CONCLUSÕES}

Conclui-se, portanto, ao final deste breve ensaio, a partir das premissas estabelecidas, no sentido de que o processo de produção de conhecimento não passa apenas pelos métodos da ciência tradicional, mas que se estabelece com a relação dialética e produtiva com outros métodos de produção do conhecimento, que estabelece o ponto de partida para uma análise sobre os métodos a serem aplicados hodiernamente em ciência do Direito.

Verificou-se que os métodos tradicionais da ciência do direito, devido a sua pressuposição última se remeter à esfera da metafísica, não são suficientes para suprir as demandas que se estabelecem para o sistema jurídico. Desta forma, procurou-se estabelecer alguns parâmetros iniciais de um método aos desígnios que se colocam ao Direito, no sentido de proporcionar um método adequado às suas características contemporâneas.

Almeja-se, logo, uma metodologia científica que dialogue com os elementos que compõem o Direito em todas as suas esferas, estabelecendo-se um elo constante com o que há de mais inerente aos destinatários da norma jurídica, as suas características históricas, sociais e políticas, atrelado a uma análise crítica da sociedade.

Assim, o maior desafio do sistema jurídico é desenvolver cientistas e aplicadores do direito conscientes de seus papeis sociais e ativos na solução de conflitos interindividuais e coletivos. A consciência do jurista como agente transformador e reformador da sociedade, desenvolvido no âmbito do método dialético, denota em um profissional com o conhecimento prático e social necessário ao bom uso do Direito. 
A ciência do Direito, por sua vez, deve ser calcada sob o viés da aplicabilidade real das normas jurídicas, bem como pela sua plena eficácia social, buscando meios de cognição e interpretação das demandas postas socialmente. Apresenta-se o método dialético como instrumento para atingir esse fim, para que o sistema jurídico, em todas as suas esferas, se estabeleça como instrumento de justiça.

\section{REFERÊNCIAS BIBLIOGRÁFICAS}

AFTALIÓN, Enrique R.; VILANOVA, José; RAFFO, Julio. Introducción al derecho. Buenos Aires: Abeledo-Perrot, 2004.

ATLAN, Henri. Será que a ciência cria valores? O bom, o verdadeiro e o poeta. In: PESSISPASTERNAK, Guitta. A ciência: Deus ou Diabo? Tradução de Edgard de Assis Carvalho e Mariza Perassi Bosco. São Paulo: Unesp, 2001.

BACHELARD, Gaston. A formação do espírito científico. Contribuição para uma psicanálise do conhecimento. Tradução de Estela dos Santos Abreu. Rio de Janeiro: Contraponto, 1996.

. Conhecimento comum e conhecimento científico. In: Tempo Brasileiro São Paulo, n. 28, p. 47-56, jan-mar 1972.

. O racionalismo aplicado. Rio de Janeiro: Zahar, 1977.

. Os Pensadores. São Paulo: Nova Cultural, 1988.

O novo espírito científico. Lisboa: Edições 70, 1996a.

. A poética do devaneio. São Paulo: Martins Fontes, 1988.

CHALMERS, A. F. O que é ciência afinal? Tradução de Raul Filker. Brasília: Editora Brasiliense, 1993.

CRUZ, Álvaro Ricardo de Souza. O discurso científico na modernidade: o conceito de paradigma é aplicável ao direito? Rio de Janeiro: Lumen Juris, 2009.

DAMÁSIO, António R. E o cérebro criou o homem. Tradução de Laura Teixeira Motta. São Paulo: Companhia das Letras, 2011.

FEYERABEND, Paul. A ciência em uma sociedade livre. Tradução de Vera Joscelyne. São Paulo: Unesp, 2011.

GADAMER, Hans-Georg. Verdade e Método II: complementos e índice. Trad. Ênio Paulo 
Giachini; Ver. Marcia Sá Cavalcante Schuback. ed. 6. Petrópolis: Vozes, 2011.

O problema da consciência histórica. Organizador: Pierre Fruchon; Tradução

Paulo César Duque Estrada. ed. 3. Rio de Janeiro: FGV, 2006.

HESSEN, Johannes. Teoria do conhecimento. Tradução de João Vergílio Gallerani Cuter. 3. ed. São Paulo: Martins Fontes, 2012.

JAPIASSÚ, Hilton. Para ler Bachelard. Rio de Janeiro: Francisco Alves, 1976. (Série Para ler).

KANT, Immanuel. Crítica da razão pura. Tradução de Manuela Pinto dos Santos e Alexandre Fradique Morujão. 5.ed. Lisboa: Fundação Calouste Gulbenkian, 2001, Introdução, itens I, II e III.

KELSEN, Hans. Teoria Pura do Direito. Tradução de João Baptista Machado. São Paulo: Martins Fontes, 2003.

KUHN, Thomas S. A estrutura das revoluções científicas. Tradução de Beatriz Vianna Boeira e Nelson Boeira. 9.ed. São Paulo: Perspectiva, 2005.

LYRA FILHO, Roberto. Normas jurídicas e outras normas sociais. In: SOUSA JÚNIOR, José Geraldo de. Introdução Crítica ao Direito, ed. 4. Brasília, UnB, 1993.

MACHADO SEGUNDO, Hugo de Brito. Por que dogmática jurídica? Rio de Janeiro: Forense, 2008.

MARQUES NETO, Agostinho Ramalho. A ciência do Direito: conceito, objeto, método. 2.ed. Rio de Janeiro: Renovar, 2001.

MIRANDA, Pontes de. O problema fundamental do conhecimento. Campinas: Bookseller, 1999.

POPPER, Karl. O conhecimento e o problema corpo-mente. Tradução de Joaquim Alberto Ferreira Gomes. Lisboa: Edições 70, 2009.

Realismo. In: MILLER, David (Org.). Popper: textos escolhidos. Tradução de Vera Ribeiro. Rio de Janeiro: Contraponto, 2010.

A vida é aprendizagem. Epistemologia evolutiva e sociedade aberta. Tradução de Paula Taipas. Lisboa: Edições 70, 2001.

A lógica das ciências sociais. Tradução de Estévão de Rezende Martins. 3.ed. Rio de Janeiro: Tempo Brasileiro, 2004.

O problema da indução. In: MILLER, David (Org.). Popper: textos escolhidos. Tradução de Vera Ribeiro. Rio de Janeiro: Contraponto, 2010. 
RESCHER, Nicholas. Epistemology. An introduction to the theory of knowledge. Albany: State University of New York Press, 2003.

RODRIGUES, Horácio Wanderley; GRUBBA, Leilane Sorratine. O direito como um processo emancipatório: a epistemologia dialética no Brasil. In: Argumenta: revista do programa de mestrado em ciência jurídica da UNENP. N ${ }^{\circ}$ 18. Jacarezinho: UNENP, 2013, p. $31-62$.

SANTOS, Boaventura de Sousa. Um discurso sobre as ciências. 6.ed. São Paulo: Cortez, 2009.

Par um novo senso comum: a ciência, o direito e a política na transição paradigmática. 8. ed. São Paulo: Cortez, 2011.

SOKAL, Alan. Pseudoscience and postmodernism: antagonists or fellow-travelers? In: FAGAN, Garrett (ed.). Archaeological fantasies: How pseudoarchaeology misrepresents the past and misleads the public. New York: Routledge, 2006. 